\title{
ANALISA USABILITY DESAIN USER INTERFACE PADA WEBSITE TOKOPEDIA MENGGUNAKAN METODE HEURISTICS EVALUATION
}

\author{
Rifda Faticha Alfa Aziza ${ }^{1)}$, Yahya Taufiq Hidayat ${ }^{2)}$ \\ 1), 2) Fakultas Ilmu Komputer, Universitas AMIKOM Yogyakarta \\ Jl. Ring Road Utar, Condong Catur, Depok, Sleman, Yogyakarta 55281

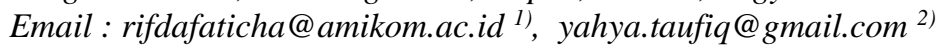

\begin{abstract}
Abstrak
User interface merupakan salah satu faktor terpenting dalam membangun sebuah website. Tanpa persiapan dan perancangan yang matang, suatu website tertentu tidak bisa berjalan secara maksimal, bahkan bisa mengakibatkan user berpindah ke website lain.

Penelitian ini bertujuan untuk mengevaluasi desain user interface yang diterapkan pada website Tokopedia menggunakan metode Heuristics Evaluation. Metode ini memiliki 10 aspek user interface yang menjadi parameter apakah user interface tersebut berinteraksi terhadap user dengan baik atau tidak. Cara kerja metode ini yaitu dengan meminta responden mengisi kuisioner yang berisi beberapa pertanyaan yang berkaitan dengan 10 aspek user interface dari metode ini, untuk ditarik hasil kesimpulan dan saran. Sehingga melalui paper ini, didapatkan catatan-catatan penting demi perbaikan dan pengembangan kualitas website Tokopedia sendiri dan website e-commerce lain kedepannya, agar perkembangan e-commerce di Indonesia semakin meningkat.

Pada penelitian analisa usability dengan objek Website Tokopedia dengan total 40 responden ini mendapatkan nilai Severity Rating rata-rata 1 (Satu), dengan kata lain, Website Tokopedia mempunyai kekurangan atau kendala yang tidak dipermasalahkan atau berdampak besar bagi pengguna.
\end{abstract}

Kata kunci: User Interface, Usability, Heuristics Evaluation, Website, Tokopedia.

\section{Pendahuluan}

User interface merupakan serangkaian tampilan grafis yang dapat dimengerti oleh pengguna komputer dan diprogram sedemikian rupa sehingga dapat terbaca oleh sistem operasi komputer dan beroperasi sebagaimana mestinya (Darmawan R, 2013).

User interface adalah salah satu faktor yang menentukan peningkatan traffic pada sebuah website. Karena user berinteraksi dengan logika pemrograman melalui user interface. Dan desain user interface sendiri menjadi sangat penting mengingat semakin efektif dan efisien suatu desain, semakin betah pula user untuk berlamalama di website tersebut (Gerald L. Lohse, 1998).

Untuk mengetahui apakah usability sebuah website sudah efektif dan efisien dibutuhkan sebuah evaluasi. Terdapat 4 cara untuk mengevaluasi suatu user interface.
Cara Formal yaitu dengan teknik analisis, Cara Otomatis yaitu dengan prosedur dari sebuah program terkomputerisasi, Cara Empiris yaitu dengan percobaan dengan test user, dan Cara Heuristik yaitu dengan meminta user untuk melihat secara sekilas interfacenya, dan langsung dimintai pendapat tentang penilaiannya (Jukob Nielsen, 1990).

Pada analisa ini penulis menggunakan cara yang keempat, yaitu cara Heuristik. Alasan penulis memakai metode ini dikarenakan pertumbuhan pengguna internet, secara khusus di Indonesia, yang semakin meningkat $0.84 \%$ setiap tahunnya, dan $32 \%$ dari total user diatas yang mengakses website e-commerce. (Jukob Nielsen, 1994)

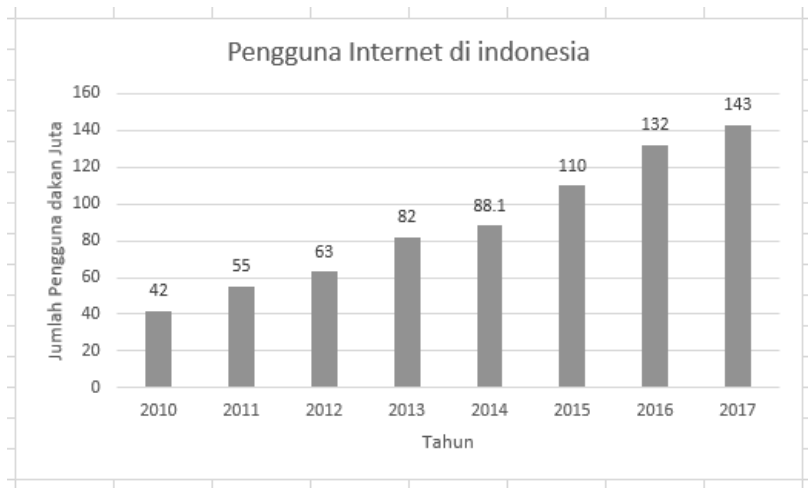

Gambar 1. Grafik Pengguna Internet di Indonesia

Objek yang penulis ambil dalam penelitian kali ini adalah Website Tokopedia. Misi Website Tokopedia adalah pemerataan ekonomi di Indonesia secara Digital.Tokopedia merupakan sebuah website jual beli online / toko online (e-commerce) di Indonesia yang mengusung model bisnis marketplace. Target pasar Tokopedia adalah para penjual dan pembeli, dimana Tokopedia menyediakan tempat bagi penjual untuk memasarkan barangnya, serta pembeli yang bisa melihat dan memilih barang yang akan dibeli. Transakasi antara penjual dan pembeli di Tokopedia menggunakan sistem Rekening Bersama, yaitu ketika uang dari pembeli ditahan terlebih dahulu di rekening milik Tokopedia, dan saat barangnya telah sampai di tangan pembeli barulah uang yang ditahan tersebut diteruskan ke rekening penjual. Sejak didirikan pada 17 Agustus 2009 dan masih berjalan sampai sekarang, rata-rata kunjungan perbulan situs Tokopedia pada triwulan ke-3 tahun 2018 mencapai 153.64 juta kunjungan, mengalahkan Bukalapak dan juga Shopee (IPRICE, 2018). 


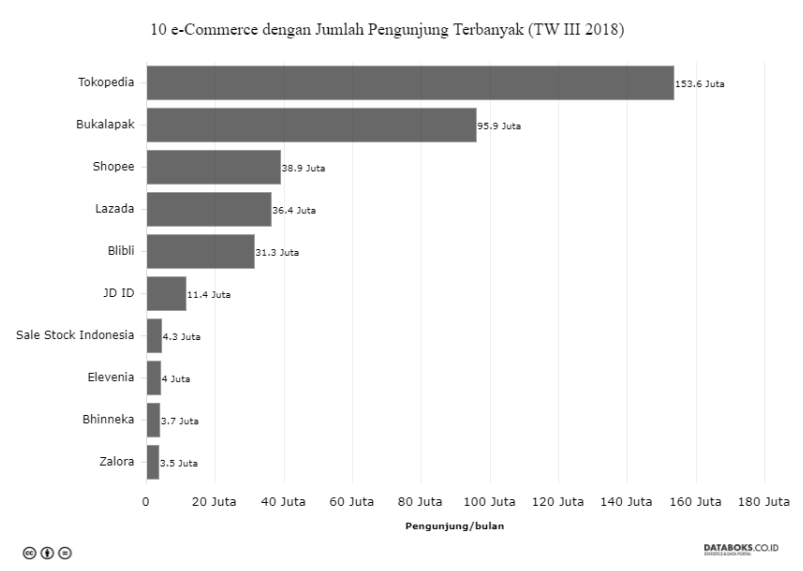

Gambar 2. Grafik jumlah pengunjung website ecommerce Indonesia triwulan ke-3 tahun 2018 [iprice.co.id 2018]

Tujuan ditulisnya makalah ini adalah untuk mengevaluasi website Tokopedia agar didapatkan jawaban mengapa website Tokopedia bisa menghasilkan kunjungan perbulan hingga mencapai 153.64 juta kunjungan serta diharapkan melalui makalah ini bisa menjadi batu loncatan dalam mengembangkan user interface pada website e-commerce lain dalam aspek desain User Interface.

\section{Tinjauan Pustaka}

Human and Computer Interaction (HCI, Interaksi Manusia dan Komputer) merupakan satu disiplin ilmu yang mempelajari komunikasi atau interaksi antara pengguna dan sistem, entah itu sistem dalam komputer, atau sistem lain yang ada pada kehhidupan sehari-hari. Peran utama dari HCI ini adalah untuk menghasilkan sebuah sistem yang mudah digunakan, aman, efektif dan efisien (Sudarmawan, 2007).

\section{Heuristics Evaluation oleh Jakob Nielson}

Seperti dijelaskan di awal pendahuluan, Heuristik adalah guideline, prinsip umum dan peraturan, serta pengalaman yang bisa membantu suatu keputusan atau kritik atas suatu keputusandan beberapa penilaian yang tekah diambil terhadap suatu desain supaya dapat memajukan potensi usability (Sudarmawan, 2007). Sepuluh aspek yang dinilai dalam metode Heuristics Evaluations menurut Jakob Nielsen (Jukob Nielsen, 1990) dan yang penulis masukkan dalam kuisionernya adalah sebagai berikut:

1) Visibilitas status sistem

Berisi pertanyaan tentang navigasi halaman tempat user berada, notifikasi, keunikan tombol.

2) Kecocokan antara sistem dan dunia nyata

Berisi keunikan dan kejelasan ikon perintah, opsi menu, judul menu menggunakan tata bahasa dan gaya yang konsisten, penggunaan istilah yang sesuai.

3) Kontrol dan kebebasan pengguna
Berisi dialog konfirmasi ketika akan melakukan perintah yang tidak bisa dibatalkan, fitur membatalkan setiap tindakan (undo), membatalkan tindakan yang sedang berlangsung dan kontrol yang sederhana.

4) Standarisasi dan konsistensi

Berisi konsitensi ikon, bahasa dan istilah pada website, kontrol, nama-nama opsi menu, dan kode warna.

5) Pemahaman daripada ingatan

Berisi pertanyaan tentang perbedaan pilihan menu antara yang aktif dan tidak aktif, penempatan tombol menu yang konsisten, dan peletakan elemen grafis yang muncul ketika dibutuhkan.

6) Fleksibilitas dan efisiensi penggunaan

Berisi pertanyaan tentang ketersediaan opsi lanjutan, pintasan ketika akan menjalankan perintah dan kemudahan mengakses informasi yang diinginkan.

7) Pencegahan kesalahan

Berisi pertanyaan tentang notifikasi / dialog ketika akan membuat kesalahan yang serius, website dapat mencegah kesalahan yang dilakukan oleh pengguna, dapat memberikan petunjuk mengisi data untuk mencegah kesalahan serta menu pilihan logis, unik dan dapat dibedakan.

8) Estetika dan desain minimalis

Berisi pertanyaan tentang kejelasan informasi dari sebuah perintah, ikon yang mewakili perintah saling terkait, layar entri data mnyertakan judul yang sederhana pendek dan jelas, serta tindakan / perintah utama dapat dibedakan secara visual dari alur alternatif.

9) Membantu pengguna untuk mengenali, mendiagnosa, dan memulihkan dari error

Berisi pertanyaan tentang ketersediaan informasi ketika terjadi kesalahan, dengan bahasa yang mudah dimengerti, jelas dan ringkas, serta menyarankan jalan keluar dari kesalahan atau masalah tersebut.

10) Bantuan dan dokumentasi

Berisi pertanyaan tentang keakuratan bantuan dan dokumentasi, lokasi terorganisir, dokumentasi memungkinkan pengguna untuk memahami dan dapat melanjutkan langkah perintahnya dengan benar, dapat diakses dengan mudah tanpa mengganggu pekerjaan serta dapat melanjutkan pekerjaan tersebut.

\section{Metode Penelitian}

Metode yang diterapkan dalam penelitian ini yaitu dengan melakukan studi literatur tentang Interaksi Manusia dan Komputer, serta teori "Heuristics Evaluation" Jakob Nielsen dan Rolf Molich. Dimana dari metode tersebut digunakan sebagai acuan dalam 
melakukan evaluasi usability desain user interface (Jukob Nielsen, 1994). Langkah selanjutnya adalah dengan menyebar kuisioner ke responden untuk menilai desain user interface melalui pertanyaan yang berdasar dari metode "Heuristic Evaluation". Lalu hasil dari jawaban responden tersebut dikumpulkan dan diproses untuk ditarik kesimpulan dan saran untuk tujuan pengembangan sistem Website Tokopedia sendiri atau bagi Website e-Commerce lainnya. Alur metode penelitian secara garis besar bisa dilihat pada Gambar 4.

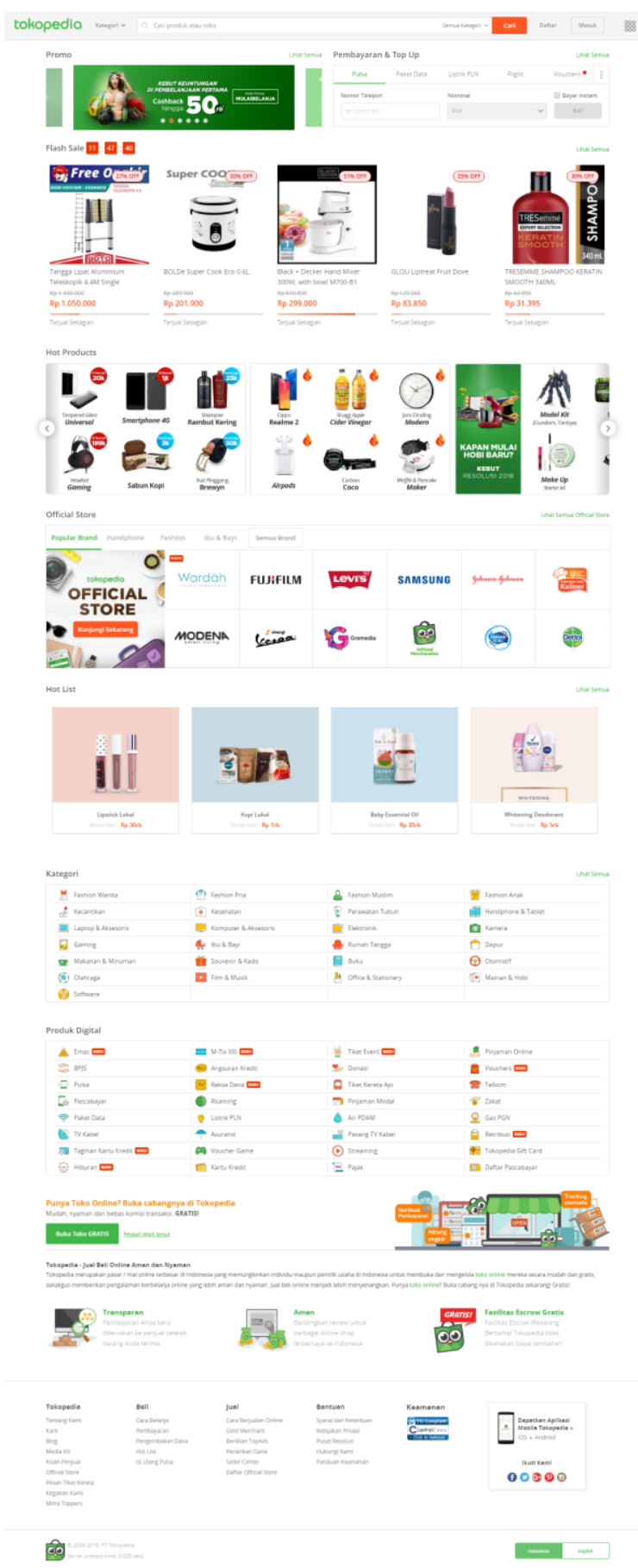

Gambar 3. Screenshot homepage website Tokopedia [diambil pukul 20.12 tanggal 14 November 2018]

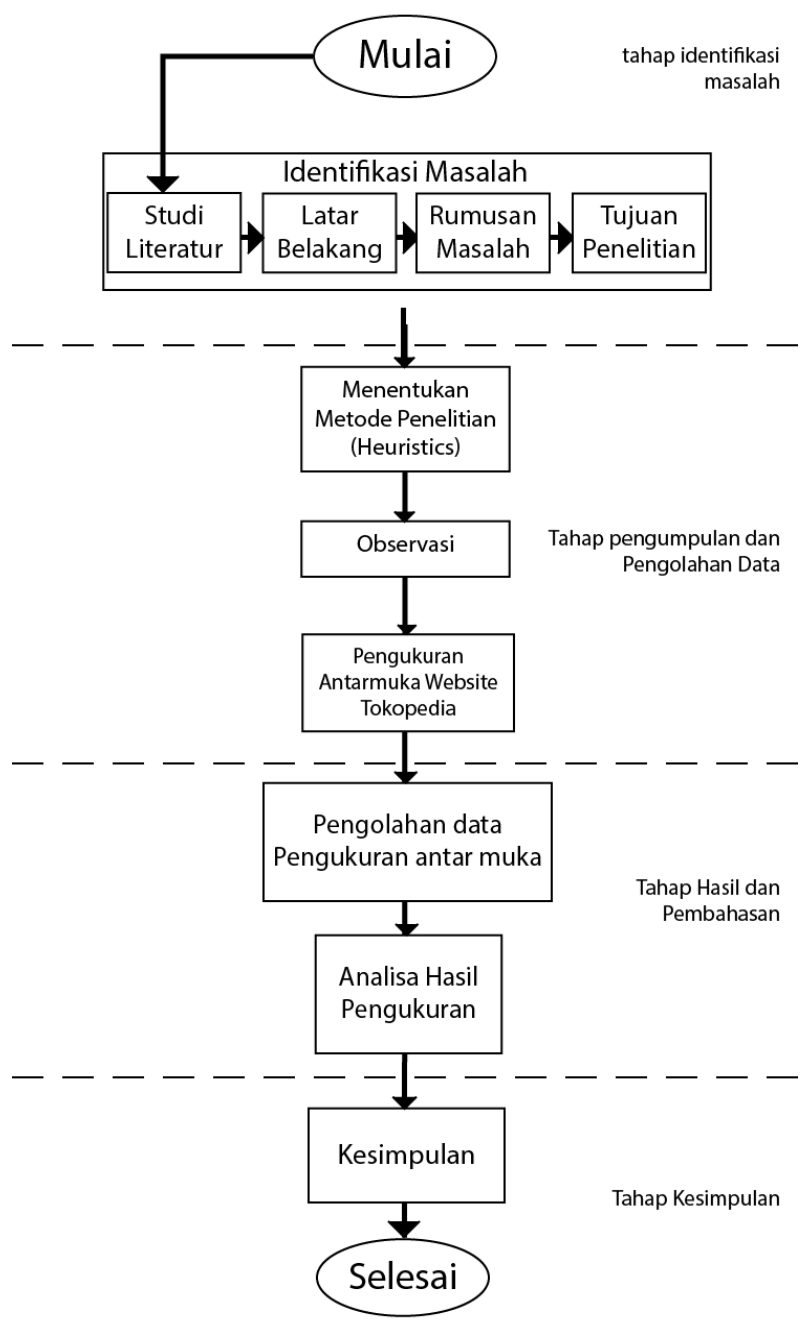

Gambar 4. Alur metode penelitian secara garis besar

Perhitungan pada evaluasi heuristik digunakan persamaan sebagai berikut (1) (Lilis Dwi, 2015).

$$
\sum \mathrm{A}=(0 * \mathrm{X})+(1 * \mathrm{X})+(2 * \mathrm{X})+(3 * \mathrm{X})+(4 * \mathrm{X})
$$

Keterangan :

$\sum \mathrm{A} \quad$ : jumlah skor rating dari sub-aspek usability dalam setiap aspek usability (A1, A2, ..., A13)

Nilai 0-4 : nilai dari Severity Rating

$\mathrm{X} \quad$ : poin usability, bernilai 1/0 (1: Ya, 0: Tidak)

untuk menghasilkan nilai severity rating dari tiap aspek usability digunakan persamaan (2):

$$
\mathrm{S}=\left(\sum \mathrm{A}\right) / \mathrm{n}
$$

Keterangan:

S: $\quad$ hasil severity rating dalam satu aspek usability

$\sum$ A: jumlah skor rating dari sub-aspek usability dalam setiap aspek usability (A1, A2,

$\mathrm{n}$ : banyaknya sub-aspek usability dalam setiap aspek usability 


\section{Pembahasan}

Pada penelitian ini digunakan skala angka 0 sampai 4 untuk menilai severity rating. Semakin kecil angkanya semakin setuju responden tentang fitur yang sudah ada dan tidak perlu ditambahkan. Sebaliknya, semakin tinggi angka skalanya, semakin tinggi dan semakin pentingnya fitur yang dibutuhkan oleh user dan harus ada di websitenya. Keterangan lebih lanjut terkait dengan skala severity rating dapat dilihat pada tabel 1 berikut (Jukob Nielsen, 1995).

Tabel 1. Detail klasifikasi severity rating

\begin{tabular}{|c|l|}
\hline Severity Rating & Keterangan \\
\hline 0 & tidak masalah \\
\hline 1 & masalah tidak penting, tidak apa-apa, \\
\hline 2 & sedikit masalah, prioritas rendah, \\
\hline 3 & masalah, prioritas sedang, \\
\hline 4 & masalah sekali, prioritas tinggi, \\
\hline
\end{tabular}

Evaluasi heuristic pada desain antarmuka website Tokopedia ini melibatkan 50 orang partisipan yang terdiri dari berbagai macam background, antara lain 50\% mahasiswa Informatika, 30\% pengajar universitas, dan $20 \%$ sisanya adalah lain-lain. Diketahui juga prosentasi jenis kelamin reponden yaitu sebesar $70 \%$ laki-laki dan $30 \%$ perempuan, dengan kisaran umur 14 - 29 tahun. Dari keseluruhan partisipan, 99\% diantaranya dinyatakan sudah pernah melakukan pembelanjaan di online marketplace. Dari hasil kuesioner yang telah diisi oleh partisipan tersebut dilakukan perhitungan severity rating untuk masing-masing aspek.

Berdasarkan hasil kuesioner dinyatakan bahwa 10 aspek dari metode heuristic oleh Nielsen memiliki nilai severity rating 1 (satu) yang berarti bahwa kesalahan atau kekurangan dapat ditolerir oleh pengguna. Dengan kata lain masalah usability yang terdapat pada website Tokopedia tidak dipermasalahkan oleh user dan dianggap tidak mengganggu pengguna saat mengakses website Tokopedia. Nilai severity rating tertinggi yaitu terdapat pada aspek fleksibilitas dan efisiensi penggunaan dengan nilai severity rating sebesar 1,15 . Untuk hasil pengolahan data kuesioner evaluasi heuristic website Tokopedia secara lengkap dapat dilihat pada tabel 2 berikut.

Tabel 2. Hasil pengolahan nilai severity rating.

$A=$ hasil mentah dengan 2 angka di belakang koma $B=$ hasil A dibulatkan ke bilangan bulat

\begin{tabular}{|c|l|c|c|}
\hline \multirow{2}{*}{ No } & \multicolumn{2}{|c|}{ Aspek Usablity } & \multicolumn{2}{|c|}{ Website Tokopedia } \\
\cline { 3 - 4 } & $\begin{array}{l}\text { Visibilitas status } \\
\text { sistem }\end{array}$ & 0,91 & 1 \\
\hline 2 & $\begin{array}{l}\text { Kecocokan } \\
\text { antara sistem dan } \\
\text { dunia nyata }\end{array}$ & 1 & 1 \\
\hline 3 & $\begin{array}{l}\text { Kontrol dan } \\
\text { kebebasan } \\
\text { pengguna }\end{array}$ & 1,03 & 1 \\
\hline
\end{tabular}

\begin{tabular}{|c|l|c|c|}
\hline 4 & $\begin{array}{l}\text { Konsistensi dan } \\
\text { standar }\end{array}$ & 0,96 & 1 \\
\hline 5 & $\begin{array}{l}\text { Pemahaman } \\
\text { daripada ingatan }\end{array}$ & 0,99 & 1 \\
\hline 6 & $\begin{array}{l}\text { Fleksibilitas dan } \\
\text { efisiensi } \\
\text { penggunaan }\end{array}$ & 1,15 & 1 \\
\hline 7 & $\begin{array}{l}\text { Pencegah } \\
\text { kesalahan }\end{array}$ & 1,01 & 1 \\
\hline 8 & $\begin{array}{l}\text { Desain estetis } \\
\text { dan minimalis }\end{array}$ & 1,05 & 1 \\
\hline 9 & $\begin{array}{l}\text { Membantu } \\
\text { pengguna untuk } \\
\text { mengenali, } \\
\text { mendiagnosa, } \\
\text { dan memulihkan } \\
\text { dari error }\end{array}$ & 0,93 & 1 \\
\hline 10 & $\begin{array}{l}\text { Bantuan dan } \\
\text { dokumentasi }\end{array}$ & 1,09 & \\
\hline
\end{tabular}

Tabel diatas adalah hasil rata-rata dari beberapa pertanyaan yang mempunyai kesamaan aspek. Nilai severity rating diambil dari pertanyaan-pertanyaan secara langsung yang terdapat di kuesioner.

Dari beberapa pertanyaan yang terdapat di kuesioner, ada pertanyaan-pertanyaan pada beberapa aspek yang mempunyai severity rating tinggi.Berikut adalah tiga pertanyaan yang memiliki severity rating paling tinggi.

1. Aspek fleksibilitas dan efisiensi penggunaan memiliki nilai severity rating paling tinggi yaitu 1,15. Pada aspek ini masalah terdapat pada kurangnya menu pintasan sehingga pengguna tidak bisa menjalankan perintah tertentu dengan mudah. Severity rating pertanyaan ini bernilai 1,24.

Menurut pengguna, dibutuhkan pintasan pada keyboard untuk menjalankan perintah atau menuju ke menu tertentu. Misal: tombol F pada keyboard untuk mengarahkan kursor ke kolom pencarian, tombol $\mathrm{C}$ untuk menuju daftar chart.

2. Aspek konsistensi dan standar memiliki nilai severity rating 0,96 . Menurut pengguna, warna pada Tokopedia belum konsisten, hal ini diperjelas dengan nilai severity rating pertanyaan mengenai konsistensi warna yang mendapatkan nilai 1,18.

3. Pada aspek bantuan dan dokumentasi terdapat masalah pada letak informasi bantuan yang memiliki severity rating bernilai 1,18 .

Menurut pengguna, lebih baik dokumentasi bantuan pada website Tokopedia diletakkan pada halaman yang sama (pop up dialog box) sehingga pengguna tidak harus meninggalkan task yang sedang dijalankan dan bisa membaca dokumentasi sambil melanjutkan task tersebut. 
Pada bagian terakhir kuisioner penulis, terdapat beberapa fitur yang menurut responden sangat berkesan. Tiga diantaranya sebagai berikut.

1. Terdapat fitur record jumlah barang yang sudah terjual, rating, review, dan menu diskusi. Sehingga pengguna/konsumen baru atau lama bisa membedakan mana penjual yang mempunyai kredibilitas yang baik dan mana yang buruk.

2. Secara keseluruhan, desain User Interface dan User Experience-nya sudah bagus.

3. Informasi produk jelas, berada dalam satu halaman dan proses untuk pembelian ringkas

Dan ada kolom khusus terhadap fitur yang tidak ada pada website Tokopedia tetapi lebih baik ada.

1. Loading dalam membuka Website Tokopedia yang tergolong lambat, sehingga menghambat pengguna yang membutuhkan kecepatan.

2. Tampilan web melalui mobile yang kruang minimalis untuk lebih disederhanakan kembali.

\section{Kesimpulan}

Dari hasil analisa dan pembahasan sebelumnya, dapat ditarik kesimpulan dan saran sebagai berikut:

Berdasarkan pengukuran Website Tokopedia menggunakan metode evaluasi heuristic oleh Nielsen didapatkan bahwa 10 aspek yang diteliti mendapatkan nilai 1 (satu), yang berarti Website Tokopedia memiliki beberapa kekurangan yang tidak menjadikan sebuah masalah atau dengan kata lain tidak dipermasalahkan dan tidak mengganggu pengguna saat mengakses website Tokopedia. Nilai severity rating tertinggi terdapat pada aspek fleksibilitas dan efisiensi penggunaan.

Kemudian saran untuk penelitian selanjutnya dapat membandingkan dengan metode lain agar didapat hasil pengukuran yang maksimal.

\section{Daftar Pustaka}

NIELSEN, J. AND MOLICH, R., 1990, March. Heuristic evaluation of user interfaces. In Proceedings of the SIGCHI conference on Human factors in computing systems (pp. 249256). ACM.

ASOSIASI PENYELENGGARA JASA INTERNET INDONESIA. Infografis Penetrasi dan Perilaku Pengguna Internet Indonesia 2017. Februari 2018

IPRICE GROUP. The Map of E-commerce in Indonesia Q3 2018. https://iprice.co.id/insights/mapofecommerce/en/. Diakses 31 Oktober 2018 pukul 20.56 WIB.

SUDARMAWAN, D.A., 2007. Interaksi Manusia \& Komputer. Yogyakarta: Andi Offset.
FARIDA, D. L. 2015. Perancangan Model User Experience untuk Website Pariwisata berdasarkan pada Prinsip Usability (Studi Kasus: Pariwisata di Asia Tenggara), Teknik Elektro dan Teknologi Informasi. Universitas Gadjah Mada.

NIELSEN, J., 1994, April. Usability inspection methods. In Conference companion on Human factors in computing systems (pp. 413-414). ACM.

NIELSEN, J., 1995. Severity ratings for usability problems. Papers and Essays, 54, pp.1-2.

DARMAWAN, R., 2013. Pengalaman, Usability, dan Antarmuka Grafis: Sebuah Penelusuran Teoritis. Journal of Visual Art and Design, 4(2), pp.95-102.

LOHSE, G.L. AND SPILLER, P., 1999. Internet retail store design: How the user interface influences traffic and sales. Journal of Computer-Mediated Communication, 5(2), p.JCMC522. 